\title{
MALÁRIA HUMANA: PADRONIZAÇÃO E OPTIMIZAÇÃO DE TESTES SOROLÓGICOS PARA DIAGNÓSTICO INDIVIDUAL E INQUÉRITOS SOROEPIDEMIOLÓGICOS
}

\author{
Antonio Walter FERREIRA (1, 2) \& Maria Carmen Arroyo SANCHEZ (1)
}

\begin{abstract}
RESUMO
O teste de imunofluorescência indireta (IFI) é considerado teste de referência na sorologia da malária. Neste trabalho procuramos optimizar o teste empregando $\mathbf{P}$. falciparum obtido de sangue humano e de cultura e $\mathbf{P}$. vivax obtido de sangue de paciente como antigenos, para pesquisa de anticorpos IgG e IgM. Das variáveis técnicas estudadas melhores resultados foram obtidos quando os soros foram diluidos em PBS contendo 1\% de Tween 80 e as lâminas contendo a suspensào antigênica foram estabilizadas en dessecadores ou fixadas com acetona. Foi também padronizado o teste imunoenzinático ELISA com antígenos de P. falciparum obtidos em cultura. O estudo comparativo com o teste de imunoftuorescência indireta para pesquisa de anticorpos Ig G mostrou: a) nos pacientes primo infectados por $\mathbf{P}$. falciparum a sensibilidade para ambos os testes foi de $71 \%$; b) nos pacientes primo infectados pelo P. vivax a sensibilidade foi de $40 \%$ para ambos os testes; c) nos pacientes não primo infectados e com malária at ual pelo $\mathbf{P}$. falciparum a sensibilidade para ambos os testes foi de $100 \%$; d) nos pacientes nào primo infectados e com malária atual pelo $\mathbf{P}$. vivax a sensibilidade foi de $85 \%$ para o teste ELISA e de $92 \%$ para a IFI; e) nos pacientes com malária mista a sensibilidade para ambos os testes foi de $100 \%$. A especificidade da IFI foi de $100 \%$ e do teste ELISA $95 \%$ nos casos de individuos não maláricos.

Os resultados obtidos sugerem ser o teste ELISA, uma boa alternativa para o teste de IFI, para a pesquisa de anticorpos IgG anti P. falciparum, na sorologia da malária.
\end{abstract}

UNITERMOS: Malária; IFI; Teste imunoenzimático ELISA.

\section{INTRODUÇĀO}

A malária continua sendo a doença de maior prevalência no mundo, principalmente nas regiōes tropicais onde permanece hiper ou holoendêmica. Estima-se em 300 milhôes de ca-

(1) Laboratório de Soroepidemiologia do Instituto de Medicina Iropical de São Paulo. São Paulo, SP, Brasil.

(2) Departamento de Moléstias Intecciosas e Parasitárias da Faculdade de Medicina da Universidade de São Paulo. São Paulo, SP, Brasil.

Endereço para correspondência: Dr. Antonio Walter Ferrcira. Laboratório de Imunologia do Instituto de Medicina Tropical de São Paulo. Av. Dr. Enéas de Carrahho Aguiar, 470. (EP 05403 São Paulo, SP, Brasil. 
FERREIRA, A.W. \& SANCHEZ, M.C.A. - Malária humana: padronizaçào e optimização de testes sorológicos para diagnóstico individual e inqueritos soroepidemiologicos. Rev. Inst. Med, trop. São Paulo, 30(3):137-146, 1988.

sos por ano, com cerca de 3 milhões de óbitos, principalmente entre crianças. No Brasil, representa um dos mais sérios problemas de saúde pública tendo sido notificados pela SUCAM a ocorrência de mais de 500.000 casos em 1987. Alem da alıa prevalência nas áreas endêmicas, a doença assume caracteristicas importantes nas áreas já erradicadas devido ao intenso fluxo migratório existente e, casos de malária têm sido relatados principalmente, a malária póstransfusional. É obrigatório a introdução de rígidas medidas de controle, quer no campo social, quer no campo operacional. Classicamente as técnicas de campo para avaliação epidemiológica na qual as decisões operacionais são baseadas, constituem no exame de sangue e baço, na deteção de casos febris e na identificação de parasitas em gotas de sangue.

O cxame parasitológico, normalmente, é foito em individuos que apresentam febre. Porém nem todos os indivíduos com malária tem febre ou raramente dão importância aos sintomats que apresentam 17, 33. Um exame parasitológico positivo indica apenas a prevalência de ponto 1, th. Para se ter uma idéia de prevalência de período associa-se-o exame parasitológico ao indice esplênico, que é inespecifico". Um exame parasitológico negativo nem sempre é exclusivo de malária, pois falsos resultados negativos podem ocorrer quando existe baixa parasitemia, açào de drogas anti-maláricas ou nos individuos semi-imunes $4,1+, 14,21,26.27,33$. Os testes sorológicos contribuem de maneira decisiva no diagnóstico individual ou em estudos soroepidemiologicos em áreas endêmicas ou não endêmicas.

Nas áreas onde a malária é endêmica ou já foi erradicada os testes sorológicos são úteis para: medir o nivel de endemicidade, verificar a presença ou ausência de transmissão, delinear áreas malarígenas, detectar mudanças sazonais de transmissão, investigar a reintrodução de novos casos, e avaliar os programas antimaláricos $1,2,4,5,11,1,15,1,14,20,2 \times$. Nas áreas onde a doenca não é endêmica são út eis na seleção de doadores de sangue, no diagnóstico diferencial e no diagnóstico de individuos com baixa parasitemiat, $2,4.5 \cdot 15$.

Segundo a Organização Mundial da Saúde ${ }^{2}$, os métodos sorológicos, além de apresentarem boa sensibilidade, especificidade, devem serir, também para identificar as especies infectantes, para diferenciar as infecçoes atuais das pregressas, bem como a primo infecção das reinfecções, e para determinar o estado de imunidade do hospedeiro. Assim é que muitos estudos vêm sendo realizados a fim de desenvolver e aperfeiçoar testes sorológicos práticos e seguros e que satisfaçam a algum daqueles requisitos.

No presente trabalho, padronizamos e optimizamos o teste de imunofluorescencia indireta para a pesquisa de anticorpos $\operatorname{IgG}$ e IgM, o teste imunoenzimático, ELISA para antígenos plasmodiais e comparamos os testes para a pesquisa de anticorpos $\operatorname{IgG}$ anti P. falciparum e anti $\mathbf{P}$. vivax em soros de pacientes primo infectados, de pacientes com mais de uma malária, de pacientes com infeção mista e de indivíduos não maláricos.

\section{MATERIAL E MÉTODOS}

Antígenos - Plasmodium falciparum foi obtido a partir do cultivo "in vitro" $16,39,40,4 ! \mathrm{e}$ de sangue de pacientes primo infectados, não tratados com infecção recente. Plasmodium vivax foi obtido a partir de sangue de pacientes primo infectados não tratados com infecção recente.

Soros - Para padrão positivo foi selecionado um painel de soros com títulos altos e baixos obtidos a partir de pacientes com infecção atual pelo $\mathbf{P}$. vivax ou $\mathbf{P}$. falciparum confirmada pelo exame parasitológico. Para padrào negativo foi selecionado um painel de soros não reagentes obtidos a partir de indivíduos não infectados, clínica e parasitologicamente diagnosticados.

Para aplicação dos testes foram selecionados soros de indivíduos de área endêmica, primo infectados pelo P. vivax ou $\mathbf{P}$. falciparum de pacientes com mais de uma malária, de pacientes com infecção atual mista por P. falciparum e P. vivax, soros de indivíduos não maláricos e soros de bancos de sangue. Para estudo da especificidade do teste foram selecionados soros de indivíduos com outras parasitoses.

Conjugados - Os conjugados fluorescentes foram produzidos a partir da fração IgG de soro de carneiro anti IgG humano, específico para cadeias $y$ e da fração IgG de soro de carneiro anti IgM humano especifico para cadeia $\mu$. purificado por gel filtração em Sephadex G200 ou por troca iônica. Foi utilizada a técnica de conjugação de Clark e Sheppard es- 
FERREIRA, A.W. \& SANCHEZ, M.C.A. - Malária humána: padronizaçào e optimizaçào de testes sorológicos para diagnóstico individual e inqueritos soroepidemiologicos. Rer. Inst Med. trop. Sâo Paulo, 30(3):137.146. 1988

tabelecendo-se entre 2,5 e 3,0 a relaçào fluoresceina-proteína. Para produçâo dos conjugados enzimáticos foi utilizada a técnica de Nakane, 19782x. Como enzima foi utilizada a peroxidase (Horseradish Peroxidase Type VI -Sigma Chem. Co.) e estabeleceu-se entre 0,5 e 1,0 a relação enzima-proteina. Ambos conjugados, fluorescentes e enzimáticos, foram titulados por titulaçào em bloco para se estabelecer a diluição ótima de uso.

Teste de imunofluorescência indireta Após a determinação do número de hemácias parasitadas por campo, o sedimento foi lavado e suspenso em solução salina tamponada com fosfato (PBS) de acordo com a fórmula: VD = $(2,5 \times N)-1$, onde VD é o volume do diluente que deve ser adicionado sobre a papa de hemácias e $\mathrm{N}$ é o número de hemácias parasitadas por campo microscópico. As lâminas contendo a suspensào antigênica $(5 \mu$ por área determinada) foram armazenadas em freezer a $-70^{\circ} \mathrm{C}$ após serem acondicionadas em embalagens plásticas, isentas de umidade. Como variáveis foram estudados: lise das hemácias com água destilada, à temperatura ambiente por $10 \mathrm{minu}$ tos; fixaçào em acetona por 30 minutos, a $4^{\prime \prime} \mathrm{C}$; lise das hemácias e fixação em acetona e, estabilização em dessecador após retirada do freezer, por 20 minutos a temperatura ambiente. Como diluente dos soros foram utilizados PBS e PBS contendo Tween-80 a $1 \%$ (PBS-T).

Teste imunoenzimático com antigenos plasmodiais - Placas plásticas de fundo plano (NUNC) foram sensibilizadas com $100 \mu$ lde anlígeno plasmodial, obtido a partir de cultura, após concentraçào com plasmagel quando a parasitemia era menor que $5 \%$, lise das hemácias e extração dos componentes antigênicos com uréia $8 \mathrm{M}^{12}$, na concentraçào de $5 \mu \mathrm{l} / \mathrm{ml}$ (método de Warbung-Christian), previamente alcalinizado com tampão carbonato-bicarbonato $0,06 \mathrm{M} \mathrm{pH} 9.6$ por 2 horas a $37^{\circ} \mathrm{C}$ e 18 horas a $4^{\prime \prime} \mathrm{C}$. Após lavagens com PBS- $\mathrm{T}$ por três vezes as placas foram bloqueadas com soluçào a $1 \%$ soro albumina bovina (BSA) em tampào carbonato por 1 hora a $37^{\circ} \mathrm{C}$. Após novo ciclo de lavagens foram adicionados $100 \mu \mathrm{l}$ dos soros padrão positivo e padrão negativo diluidos em PBS contendo BSA a $1 \%$. Após incubação por 1 hora a $37^{\circ} \mathrm{C}$ e novo ciclo de lavagens foi adicionado $100 \mu \mathrm{l}$ de conjugado enzimát ico diluído segundo o título, em PBS-T. Após nova incubação por 1 hora a $37^{\circ} \mathrm{C}$ e novo ciclo de lavagens a reação enzimática foi relevada pela adi- ção de ortofenilenodiamina em tampão citrato pH 5,0 contendo água oxigenada. Após incubaçào por 30 minutos à temperatura ambiente e na ausência de claridade a reação enzimática foi interrompida pela adição de $\mathrm{HCl} 2 \mathrm{M}$. A leitura da placa foi feita em aparelho Minireader a $492 \mathrm{~nm}$.

O teste imunoenzimático padronizado foi aplicado para soros de indivíduos primo infectados por $\mathbf{P}$. falciparum ou $\mathbf{P}$. vivax, para individuos com infeç̧ōes mistas e para individuos nào maláricos. Para esse estudo os soros foram diluídos a 1/100 ou a 1/50 e 1/100: O título em anticorpos do soro foi calculado pelas fórmulas:

$\mathrm{T}=\log \mathrm{D}+\frac{\log \mathrm{DOD}-\log \text { DOC.O. }}{\mathrm{K}}$

para uma diluição do soro e

$\mathrm{T}=\log \mathrm{Dl}+$

$+(\log D O D 1-\log D O C .0).(\log D 2-\log D 1)$ Log DODI - Log DOD2

para duas dilulçōes do soro

$K=\frac{\triangle \log D O D}{\Delta \log D}$

D, D1 e D2 - diluições

de soro

DO $=$ densidade ópti-

ca obtida

$O$ "cut off" do teste foi determinado pela fórmula:

C.O. $=\bar{X}+2 S D$

a partir de 20 soros negativos, onde

$\overrightarrow{\mathrm{X}}=$ média aritmética dos soros não reagentes e $\mathrm{SD}=$ desvio padrão obtido

\section{RESULTADOS}

As médias geométricas dos títulos de 10 soros reagentes no teste de imunofluorescência indireta com antígenos de $\mathbf{P}$. falciparum obtidos a partir de cultura e conjugados anti IgG e anti IgM e a partir de pacientes primo infectados e conjugados anti $\lg G$ estão expressas na tabela 1 .

Também são apresentados os resultados obtidos nas diferentes variáveis técnicas estudadas. 
FERREIRA, A.W. \& SANCHEZ, M.C.A. - Malária humana: padronização e optimização de testes sorológicos para diagnóstico individual e inquéritos soroepidemiológicos. Rev. Inst. Med. trop. São Paulo, 30(3):137-146, 1988.

TABELA 1

Média geométrica dos títulos de 10 soros reagentes no teste de imunofluorescência indireta com antígenos de P. falciparum, de cultura e de sangue de pacientes primo infectados, frente a diferentes variáveis técnicas.

\begin{tabular}{|c|c|c|c|c|}
\hline \multicolumn{2}{|c|}{$\begin{array}{l}\text { Variável } \\
\text { técnica }\end{array}$} & \multicolumn{2}{|c|}{ Antígeno de cultura } & $\begin{array}{l}\text { Antígeno de sangue } \\
\text { humano }\end{array}$ \\
\hline \multirow{10}{*}{ 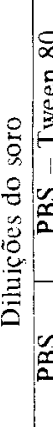 } & \multirow{6}{*}{$\begin{array}{l}\text { A } \\
\text { B } \\
\text { C } \\
\text { D }\end{array}$} & \multicolumn{2}{|c|}{ Conjugados } & \multirow{2}{*}{$\begin{array}{l}\text { Conjugados } \\
\text { anti IgG }\end{array}$} \\
\hline & & anti IgG & anti IgM & \\
\hline & & 64,98 & 15,315 & 20,00 \\
\hline & & 452,55 & 519,84 & 139,29 \\
\hline & & 64,98 & 16,24 & 21,44 \\
\hline & & 685,93 & 452,55 & 196,98 \\
\hline & A & 14,14 & SNR & SNR \\
\hline & B & 121,26 & 28,28 & 64,98 \\
\hline & $\mathrm{C}$ & 16,24 & SNR & SNR \\
\hline & $\mathrm{D}$ & 259,92 & 56,57 & 45,95 \\
\hline
\end{tabular}

Variáveis técnicas $\mathrm{A}$-- lise das hemácias com água destila$\mathrm{da} ; \mathrm{B}$ - fixação das lâminas com acetona; $\mathrm{C}$ - lise das hemácias e fixação com acetona e D - estabilização no dessecador.

SNR - todos os soros foram não reagentes.

Conforme indicado na tabela 1 os antígenos obtidos a partir de cultura forneceram maior reatividade do que os antígenos obtidos de sangue humano para a pesquisa de anticorpos IgG. Das variáveis técnicas estudadas melhores resultados foram obtidos quando as lâminas foram fixadas em. acetona ou quando sensibilizadas em dessecador com soros diluídos em PBS contendo $1 \%$ de Tween 80. Além da maior reatividade dos soros positivos, os soros não reagentes e de outras parasitoses não apresentaram nenhuma coloração de fundo que pudesse atrapalhar a interpretação dos resultados, fato observado quando os antígenos foram obtidos a partir de sangue de pacientes primo infectados.

As médias geométricas dos títulos de 10 soros reagentes no teste de imunofluorescência indireta com antígenos de $\mathbf{P}$. vivax obtidos a partir de sangue de pacientes primo infectados e conjugados anti-IgG e anti-IgM bem como as variáveis técnicas estudadas, estão expressas na tabela 2 .

Os dados apresentados na Tabela 2 mostram a maior reatividade, dos antígenos fixados em acetona ou estabilizados a temperatura ambiente em dessecador, quando diluidos em PBS contendo 1\% Tween-80.
TABELA 2

Médias geométricas dos títulos de 10 soros reagentes no teste de imunofluorescência indireta com antígenos de P. vivax obtidos de pacientes primo infectados frente a diferentes variáveis técnicas.

\begin{tabular}{|c|c|c|c|c|}
\hline \multicolumn{3}{|c|}{ Variável técnica } & \multirow{2}{*}{\multicolumn{2}{|c|}{$\frac{\begin{array}{c}\text { Antígeno de sangue } \\
\text { humano }\end{array}}{\text { Conjugado }}$}} \\
\hline \multirow{4}{*}{ 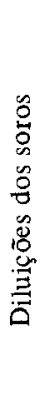 } & \multirow{3}{*}{ 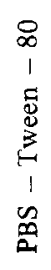 } & \multirow[b]{3}{*}{$\begin{array}{l}\mathrm{A} \\
\mathrm{B} \\
\mathrm{C} \\
\mathrm{D}\end{array}$} & & \\
\hline & & & Anti-IgG & Anti-IgM \\
\hline & & & $\begin{array}{r}260 \\
1114 \\
121 \\
1810\end{array}$ & $\begin{array}{r}\text { SNR } \\
279 \\
12 \\
320\end{array}$ \\
\hline & 望 & $\begin{array}{l}\text { A } \\
\text { B } \\
\text { C } \\
\text { D }\end{array}$ & $\begin{array}{r}\text { SNR } \\
640 \\
13 \\
597\end{array}$ & $\begin{array}{r}\text { SNR } \\
34 \\
\text { SNR } \\
49\end{array}$ \\
\hline
\end{tabular}

Variável técnica $\mathrm{A}$ - lise com hemácias com água destilada; B - fixação da lâmina com acetona; C - lise das hemácias e fixação com acetona e D - estabilização no dessecador.

SNR - todos os soros foram não reagentes.

A figura 1 mostra os resultados obtidos na padronização do teste ELISA. Das condições ensaiadas melhores resultados foram obtidos quando a concentração de antígenos foi fixada

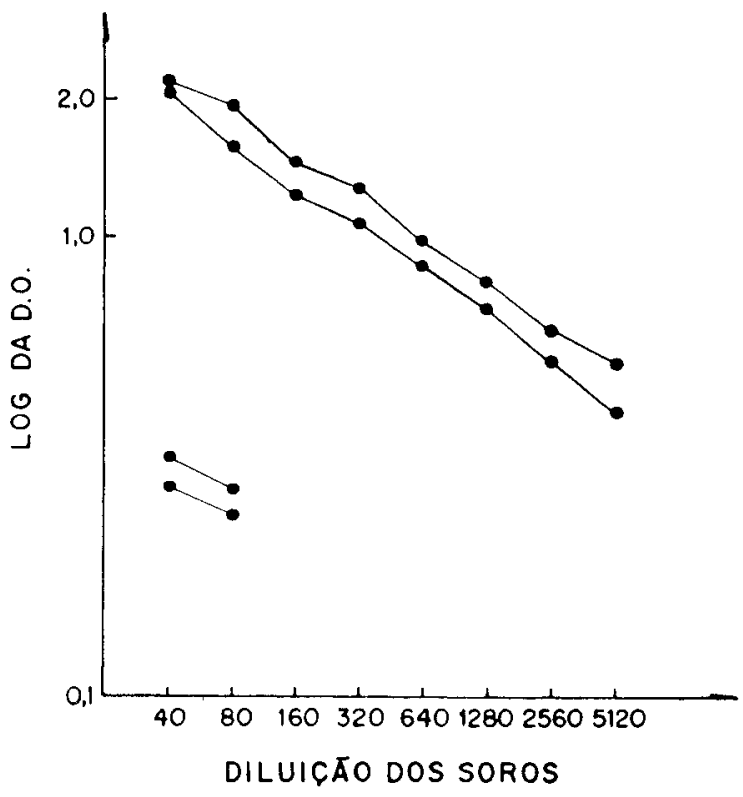

Fig. 1 - Curvas dose-resposta de soros padrão positivos e padrāo negativos, obtidos no teste ELISA, para pesquisa de anticorpos $\lg G$ anti-P. falciparum. 
FERREIRA, A. W \& SANCHEL, M.C.A. -- Malaria humana: padronizaţăo eptimização de tesies sorológicos para adiagnóstico individual e inqueritos sorvepidemiologicos. Rev. Inst. Med, trop. Säo Paulo, 30(3):137-146, 1988.

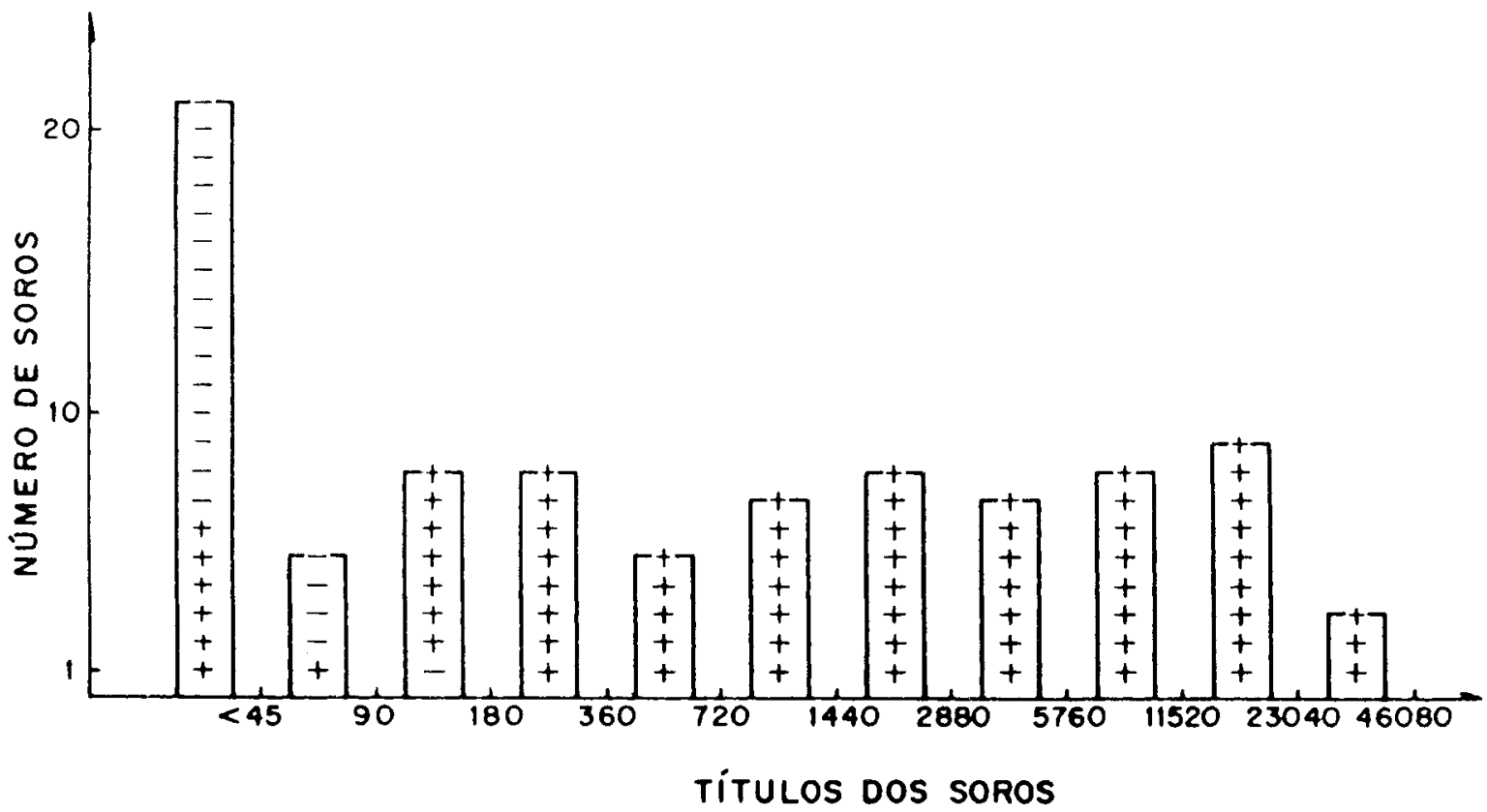

Fig. 2 - Curva de distribuiçăo de titulos en anticorpos Ig Cinti F. falcipaum no teste El.1SA obtida a partir de uma única diluicão dos soros.

em $5 \mu \mathrm{g} / \mathrm{ml}$ e as diluiçōes do conjunto em $1 / 10.000$. Nestas condiçoes obtivemos uma linearidade entre o log das densidades ópticas e as diluições dos soros.

A figura 2 mostra a curva de distribuição de títulos dos soros estudados, estabelecendo como "cut off" o título igual a 90. Como podemos observar dos 20 soros de indivíduos não maláricos, apenas 1 soro apresentou título 118 sendo considerado reagente. Dos sete soros de pacientes com malária que apresentaram títulos inferiores a 90 no teste ELISA, três eram de pacientes primo infectados pelo $\mathbf{P}$. vivax, dois eram de pacientes primo infectados pelo $\mathbf{P}$. falciparum e dois de pacientes nào primo infectados com infeccão atual pelo $P$. vivax.

$O$ estudo comparativo do teste ELISA, com componentes antigênicos de $\mathbf{P}$. falciparum e IFI com antigenos de $\mathbf{P}$. falciparum (IFI-Pf) e P. vivax (IFI-PV) está apresentado nas tabelas $3,4,5,6$ e 7 . Para os pacientes primo infectados, tabela 3, pelo P. falciparum, 2 soros foram negativos no teste ELISA, embora também fossem negativos na IFI-Pf. Nos pacientes primo infectados pelo $P$. vivax o teste ELISA foi negativo em 3 dos cinco casos estudados. $O$ mesmo resultado foi obtido no teste IFI-Pf.
Nos pacientes com mais de uma malária, tabela 4, o teste ELISA e a IFI-Pf foram positivos em todos os casos quando a infecção atual era pelo P. falciparum. Quando a infecção atual era pelo P. vivax foram observados 2 soros negativos

\section{TABELA 3}

Resultados do teste imunoenzimático, ELISA e do teste de imunofluorescência indire ta com antígeno do P. falciparum (IFI-Pf) e P. vivax (IFI-Pv) na titulação de anticorpos IgG em soros de pacientes primo infectados pelo P. falciparum (7 casos) e. Pivax ( 5 casos)

\begin{tabular}{rrr|rrr}
\hline \multicolumn{5}{c}{ Primo infecção } \\
\hline \multicolumn{7}{c}{ P. falciparum } & \multicolumn{3}{c}{ P. vivax } \\
\hline ELISA & IFI-Pf & IFI-Pv & ELISA & IFI-Pf & IFI-Pv \\
\hline 29441 & 5120 & 160 & 261 & 20 & 1280 \\
8485 & 1280 & 80 & 9 & SNR & 40 \\
1045 & 160 & SNR & 3030 & 160 & 160 \\
562 & 20 & SNR & 1 & SNR & SNR \\
187 & 80 & SNR & 1 & SNR & SNR \\
37 & SNR & SNR & - & - & - \\
17 & SNR & SNR & - & - & - \\
\hline
\end{tabular}

SNR = Soro não reagente

"Cut off" $=90$ 
FERREIRA, A.W. \& SANCHEZ, M.C.A. -- Malária humana: padronizaçào e optimização de tesces sorologicoss para diagnóstico irudividual e inquéritos soroepidemiológicos. Rev. Inst. Med. Irop. São Paulo, 30(3):137-146, 1988.

pelo teste ELISA e apenas 1 soro negativo na IFI-Pf. Nos indivíduos com infecção mista, tabela 5 , não houve diferença na reatividade do teste ELISA e IFI-Pf. O teste ELISA apresentou um falso resultado positivo nos individuos não maláricos, fato não observado no teste IFIPf, embora alguns casos tenham apresentado dificuldade na leitura microscópica. As médias geométricas dos títulos dos soros apresentados

\section{TABELA 4}

Resultados do teste imunoenzimático-ELISA e do teste de imunofluorescência indireta com antígenos de P. falciparum (IFI-Pf) ou P. vivax (IFI-Pv) na titulação de anticorpos IgG, em soros de pacientes com mais de uma malária e com episódio atual de malária-falciparum ( 34 casos) ou malária-vivax (13 casos)

\begin{tabular}{|c|c|c|c|c|c|}
\hline \multicolumn{6}{|c|}{ Infeç̧ão A tual } \\
\hline \multicolumn{3}{|c|}{ P. falciparum } & \multicolumn{3}{|c|}{ P. vivax } \\
\hline ELISA & IFI-Pf & IFI-Py & ELISA & IFI-Pf & IFI-Pv \\
\hline 2457 & 640 & SNR & 871 & 1280 & 160 \\
\hline 1319 & 640 & SNR & 993 & 320 & 2560 \\
\hline 565 & 640 & SNR & 319 & 320 & 10240 \\
\hline 10907 & 1280 & SNR & 1767 & 20 & 1280 \\
\hline 176 & 320 & SNR & 118 & 80 & 10240 \\
\hline 655 & 1280 & SNR & 187 & 320 & 20480 \\
\hline 5765 & 40000 & 160 & 30 & 20 & 10240 \\
\hline 18647 & 2560 & 320 & 455 & 80 & 40 \\
\hline 2164 & 2560 & 80 & 46 & SNR & 20 \\
\hline 18647 & 5120 & 320 & 4201 & 160 & 160 \\
\hline 18647 & 2560 & 160 & 5519 & 320 & 640 \\
\hline 10000 & 5120 & 640 & 261 & 640 & 1280 \\
\hline 13247 & 10240 & 20 & 3171 & 1280 & 640 \\
\hline 759 & 2560 & 320 & $\ldots$ & - & - \\
\hline 5967 & 1280 & 40 & - & - & - \\
\hline 1188 & 640 & 40 & - & - & - \\
\hline 3467 & 5120 & 40 & - & - & - \\
\hline 30932 & 5120 & 320 & - & - & -- \\
\hline 1880 & 640 & 160 & - & - & - \\
\hline 30932 & 2560 & 320 & .. & - & - \\
\hline 339 & 640 & 80 & - & - & - \\
\hline 1584 & 10240 & 320 & _- & - & - \\
\hline 2522 & 320 & 40 & - & - & - \\
\hline 91 & 20 & 2560 & - & - & - \\
\hline 322 & 640 & 2560 & - & - & - \\
\hline 161 & 320 & 2560 & - & -- & - \\
\hline 165 & 40 & 320 & - & - & - \\
\hline 8323 & 1280 & 1280 & - & _- & - \\
\hline 108 & 40 & 40 & _- & _- & - \\
\hline 3885 & 640 & 640 & - & - & - \\
\hline 8088 & 640 & 640 & - & - & - \\
\hline 623 & 640 & 1280 & -- & - & - \\
\hline 1960 & 640 & 320 & -. & - & -- \\
\hline 18647 & 2560 & 1280 & - & - & - \\
\hline
\end{tabular}

SNR $=$ Soro não reagente

"Cut off" $=90$

\section{TABELA 5}

Resultados do teste inunoenzimático (ELISA) e do teste de imunofluorescência indireta com antígeno de

P. falciparum (IFI-Pf) ou P. vivax (IFI-Pv) na

titulação de anticorpos IgG em soros de pacientes com infecção mista $\mathbf{P}$. falciparum ou $\mathbf{P}$. vivax

( 9 casos) ou de indivíduos não maláricos ( 20 casos).

\begin{tabular}{rrr|rll}
\hline \multicolumn{3}{c}{ Infecção Mista } & \multicolumn{3}{c}{ Não Maláricos } \\
\hline ELISA & IFI-Pf & IFI-PV & ELISA & IFI-Pf & IFI-PV \\
\hline 1894 & 2560 & SNR & 4 & SNR & SNR \\
10123 & 1280 & 80 & 25 & SNR & SNR \\
14299 & 20480 & 80 & 32 & SNR & SNR \\
15910 & 10240 & 80 & 18 & SNR & SNR \\
281 & 2560 & 640 & 18 & SNR & SNR \\
12702 & 10240 & 160 & 26 & SNR & SNR \\
4169 & 2560 & 40 & 18 & SNR & SNR \\
1239 & 640 & 640 & 11 & SNR & SNR \\
18647 & 2560 & 1280 & 2 & SNR & SNR \\
- & - & - & 13 & SNR & SNR \\
- & - & -- & 13 & SNR & SNR \\
-- & - & - & 11 & SNR & SNR \\
- & -- & - & 16 & SNR & SNR \\
- & - & - & 9 & SNR & SNR \\
- & - & -- & 22 & SNR & SNR \\
- & - & - & 118 & SNR & SNR \\
- & - & - & 83 & SNR & SNR \\
- & - & - & 46 & SNR & SNR \\
- & - & - & 57 & SNR & SNR \\
- & - & - & 77 & SNR & SNR \\
- & - & - & & & \\
\hline
\end{tabular}

SNR = Soro não reagente

"Cut off" $=90$

na tabela 6, mostram ser o teste ELISA mais reativo que a IFI-Pf, fato não observado em relação a IFI-Pv quando a infecção atual era pelo P. vivax. A tabela 7 mostra os índices de sensibilidade obtidos nos diferentes soros testados.

\section{DISCUSSÃO}

$O$ teste de imunofluorescência indireta (IFI) é o teste de referência na sorologia da malária humana $5,10,11,22,23,25,30,31,38$. Porém embora venha sendo empregado na rotina de vários laboratórios, as condições técnicas no preparo dos reagentes e na execução do teste são muito variáveis, sendo difícil estabelecer uma comparação satisfatória entre diferentes laboratórios, o que inviabiliza uma discussão clara sobre os resultados obtidos. Em relação à diluição do antígeno que deve ser colocado nas áreas delimitadas das lâminas, a maioria das 
I.ERREIRA, A.W. \& SANCHEZ, M.C.A. - Malária humana: padronização e optimização de testes sorologicos para diagnóstico individual e inquéritos soroepidemiológicos. Rev. Inst. Med. trop. São Paulo, 30(3):137-146, 1988

\section{TABELA 6}

Médias geométricas dos títulos de anticorpos IgG, obtidos pelos testes imunoensaio ELISA e imunofluorescência indireta com antígenos de P. falciparum (IFI-Pf) e P. vivax

(IFI-Pv) em pacientes com malária e em indivíduos não maláricos.

\begin{tabular}{|c|c|c|c|c|}
\hline \multicolumn{2}{|c|}{ Casuística } & ELISA & IFI-Pf & IFI-Pv \\
\hline Primo infectados & $\begin{array}{l}\text { P. falciparum } \\
\text { P. vivax }\end{array}$ & $\begin{array}{r}560 \\
23\end{array}$ & $\begin{array}{r}108 \\
20\end{array}$ & $\begin{array}{l}20 \\
61\end{array}$ \\
\hline $\begin{array}{l}\text { Não primo infec- } \\
\text { tado com infec- } \\
\text { ção atual pelo }\end{array}$ & $\begin{array}{l}\text { P. falciparum } \\
\text { P. vivax }\end{array}$ & $\begin{array}{r}2244 \\
502\end{array}$ & $\begin{array}{r}1065 \\
106\end{array}$ & $\begin{array}{l}147 \\
980\end{array}$ \\
\hline Mista & & 4855 & 3484 & 137 \\
\hline Não maláricos & & 20 & SNR & SNR \\
\hline
\end{tabular}

SNR $=$ Soro não reagente

técnicas descritas na literatura preconiza os métodos por tentativas. Com base nos trabalhos descritos por LÓPEZ-ANTUÑANO 18 e SULZER em 1969 foi feita a padronização da diluição ótima de antígenos de $\mathbf{P}$. falciparum e de $\mathbf{P}$. vivax. A fórmula final para diluição da papa de hemácias VD $=(2.5 \times \mathrm{N})-1$, onde VD é o volume do diluente necessário para ressuspender uma parte da papa de hemácias e $\mathrm{N}$ é o número médio de hemácias parasitadas com esquizontes por campo microscópico, fornece um parâmetro importante na padronização do teste. Devese considerar como ideal a diluição que fornece cerca de 20 hemácias parasitadas por campo microscópico com objetiva 40x. Determinada a diluição ótima do antígeno, foram estudadas diferentes variáveis técnicas para se obter um máximo de sensibilidade. e especificidade na IFI. Na optimização do teste de imunofluorescência indireta com antígenos de $\mathbf{P}$. falciparum para pesquisa de anticorpos IgG e $\operatorname{IgM}$, empregando-se o teste " $t$ " de Student, para amostras pareadas, verificou-se não haver diferença estatistica significativa entre as técnicas de fixação das lâminas em acetona e de estabilização das lâminas em dessecador, quando os soros foram diluidos em PBS contendo $1 \%$ de Tween-80. Esta observação foi válida tanto para a pesquisa de anticorpos $\mathrm{IgG}$, com antígenos de cultura ( $\mathrm{t}=1.5 ; \mathrm{GL}=9 ; \alpha=5 \%$ ) ou com antígenos obtidos a partir de sangue de pacientes primo infectados $(\mathrm{t}=2.3 ; \mathrm{GL}=9 ; \alpha=5 \%)$, como na pesquisa de anticorpos $\operatorname{IgM}(t=1.0$; $\mathrm{GL}=9 ; \alpha=5 \%$ ), com antigenos de cultura. Houve diferença significativa entre as técnicas de estabilização das lâminas em dessecador, com soros diluidos em PBS contendo $1 \%$ de Tween80 e as demais técnicas estudadas. Não foram pesquisados anticorpos IgM com antígenos de $\mathbf{P}$. falciparum obtidos a partir de sangue de pacientes pois a presença de anticorpos prejudica o antígeno e falsos resultados positivos ou negativos foram observados6. 34. Para o preparo do antigeno de $\mathbf{P}$. vivax a dificuldade maior relacionase com a obtenção de sangue humano. É necessário que o paciente seja primo infectado, com alta parasitemia $(+++)$ e que não tenha sido

TABELA 7

Sensibilidade do teste imunoenzimático ELISA com antígenos de $\mathbf{P}$. falciparum e do teste de imunofluorescência indireta com antígenos de P. falciparum (IFI-Pf) e P. vivax (IFI-Pv) para pesquisa de anticorpos IgG com limite de confiança de $95 \%$ de probabilidade, em pacientes com diferentes formas de malária.

\begin{tabular}{|c|c|c|c|c|}
\hline \multicolumn{2}{|l|}{ Casuística } & ELISA & IFI-Pf & IFI-Pv \\
\hline Primo infectados & $\begin{array}{l}\text { P. falciparum } \\
\text { P. vivax }\end{array}$ & $\begin{array}{l}71 \%(29,0-96,3) \\
40 \%(5,3-85,3)\end{array}$ & $\begin{array}{l}71 \%(29,0-96,3) \\
40 \%(5,3-85,3)\end{array}$ & $\begin{array}{l}29 \%(38-71) \\
60 \%(14,6-95)\end{array}$ \\
\hline $\begin{array}{l}\text { Não primo infectados com } \\
\text { infeç̧ão atual pelo }\end{array}$ & $\begin{array}{l}\text { P. falciparum } \\
\text { P. vivax }\end{array}$ & $\begin{array}{r}100 \%(89,8-100,0) \\
85 \%(54,5-98,0)\end{array}$ & $\begin{array}{r}100 \%(89,8-100,0) \\
92 \%(63,9-99,8)\end{array}$ & $\begin{array}{r}82 \%(65,5-93,2) \\
100 \%(75,3-100,0)\end{array}$ \\
\hline Mista & & $100 \%(66,4-100,0)$ & $100 \%(66,4-100,0)$ & $89 \%(15,7-99,7)$ \\
\hline
\end{tabular}


FERREIRA, A.W. \& SANCHEZ, M.C.A. - Malária humana: padronização e optimização de testes sorológicos para diagnóstico individual e inquéritos soroepidemiológicos. Rev. Inst. Med. trop. São Paulo, 30(3):137-146, 1988.

tratado. O ideal seria a obtenção de antígenos do sangue de macacos Saimiri seireus, experimentalmente infectados 9.32 . $\mathrm{Na}$ optimização do teste de imunofluorescência indireta os resultados obtidos foram semelhantes aos obtidos com antígenos de $\mathbf{P}$. falciparum. Pela análise estatística do teste " $t$ " de Student, para amostras pareadas, não houve diferença estatística significativa entre as técnicas de fixação das hemácias em acetona e de estabilização em dessecador quando, os soros foram diluídos em PBS contendo $1 \%$ de Tween-80 para a pesquisa de anticorpos $\operatorname{IgM}(\mathrm{t}=1.5 ; \mathrm{GL}=9 ; \alpha=5 \%)$. Para a pesquisa de anticorpos IgG já houve diferença estatística significativa $(\mathrm{t}=3.2 ; \mathrm{GL}=9 ; \alpha=5 \%)$. Em relação as demais técnicas sempre houve diferenças significativas. $O$ teste de imunofluorescência indireta optimizado para pesquisa de anticorpos anti $\mathbf{P}$. falciparum forneceu excelentes resultados quando aplicado em população de área endêmica ou na seleção de doadores em bancos de sangue de áreas não endêmicas. As condiçôes mencionadas neste trabalho permitirão que laboratórios de menor porte possam introduzir em sua rotina o teste de imunofluorescência indireta com resultados confiáveis.

Com relação à obtenção e preparação de componentes antigênicos de $\mathbf{P}$. falciparum a partir de cultura, procurou-se selecionar culturas com parasitemia elevada e formas em esquizontes 35 . Com parasitemias inferiores a $5 \%$ foi feita a concentração das hemácias parasitadas em Plasmagel. A utilizaçào do Plasmagel além de ser mais simples forneceu resultados superiores aos obtidos em gradientes coloidais. Com parasitemias superiores a $5 \%$ nào foi ne cessária a prévia concentração das hemácias parasitadas. Em relação à extração dos componentes antigênicos do $\mathbf{P}$. falciparum melhores resultados foram obtidos quando ao PBS foi adicionada uréia $8 \mathrm{M}$. O antígeno assim obtido foi estável, podendo ser armazenado em geladeira a $4^{\circ} \mathrm{C}$ por várias semanas. O teste imunoenzimático padronizado seguiu a metodologia descrita inicialmente por VOI L.ER em $1974^{\circ}$ e modificado por diferentes pesquisadores $3,3,35$ 31., 3., 42, 43,44.

Para aplicação do teste imunoenzimático foi inicialmente determinada a curva doseresposta frente a soros padrão positivos e negativos. Observando-se uma linearidade constante entre as diluições dos soros e o logarítimo da densidade óptica obtidas, pode-se empregar fórmulas que permitiram quantificar com pre- cisão os títulos dos soros a partir de uma ou duas diluições. A curva de distribuição dos títulos de soros de individuos com malária por $\mathbf{P}$. falciparum ou $P$. vivax e de individuos não maláricos mostrou que sete soros de pacientes primo infectados foram não reagentes no teste ELISA embora apresentassem exame parasitológico positivo. Destes, 3 casos eram primo infectados pelo $\mathbf{P}$. vivax e 2 pelo $\mathbf{P}$. falciparum, 0 que está de acordo com os dados referidos na literatura 12. 24.

O estudo comparativo do teste ELISA, e IFI com antígenos de P. falciparum (IFI-Pf) e P. vivax (IFI-Pv) para pesquisa de anticorpos $\lg G$, revelou que para soros de individuos primo infectados ambos os testes apresentavam falsos resultados negativos e que" sensibilidade foi sempre menor para o sistema heterólogo. $\mathrm{Pa}$ ra soros de pacientes não primo infectados com malária atual pelo $P$. falciparum ou mista a sensibilidade para ambos os testes, ELISA e IFI-Pf foi de $100 \%$, fato observado apenas para IFI-Pv quando os pacientes apresentavam infecção atual pelo P. vivax. Também foi observado que a média geométrica dos títulos foram sempre superiores com os sistemas homólogos.

Com relaçào à especificidade, observou-se um soro falso positivo no teste ELISA.

Os resultados obtidos no presente trabalho sugerem ser o teste ELISA uma boa alternativa para substituir o teste de imunofluorescência indireta, quando não se dispõe de microscópio de fluorescência. O que limita, no momento, a utilização do teste ELISA, em larga escala, é a obtenção de antígenos e a qualidade dos suportes inertes, além de necessitar de melhor avaliaçào nos pacientes primo infectados.

\section{SUMMARY}

\section{Human malaria: standardization of serologic tests for individual diagnostic and seroepidemiologic surveys}

The indirect immunofluorescence antibody test (IFA) is normally employed as reference test in the serology of malaria. In this report we standardized and optimized the test, for our condition, utilizing $\mathbf{P}$. falciparum obtained from human blood on culture and $P$. vivax obtained from human blood as antigens, for detection of $\operatorname{IgG}$ and $\operatorname{Ig} M$ antibodies. Some technical variables, were tested and best resulis 
FERREIRA, A.W. \& SANCHEZ, M.C.A. - Malária humana: padronização e optimização de testes sorológicos para diagnóstico individual e inquéritos soroepidemiológicos. Rev. Inst. Med. trop. São Paulo, 30(3):137-146, 1988.

were obtained when sera were diluted in PBS containing $1 \%$ Tween-80 and the slides, containing the antigenic preparation were fixed in cold acetone or stabilized on dried air with silica. The ELISA test was standardized for $\mathbf{P}$. falciparum antibodies and the comparison of the IFA and ELISA showed: a) in P. falciparum prime infected patient the sensitivity was $71 \%$ for both tests; b) in $\mathbf{P}$. vivax prime infected patients the sensitivity was $40 \%$ for both tests; c) in non prime infected patients with $\mathbf{P}$. falciparum malaria the sensitivity was $100 \%$ for both tests; d) in non prime infected patients with $\mathbf{P}$. vivax malaria the sensitivity was $85 \%$ for ELISA and $92 \%$ for IFA; e) in patients with $P$. vivax and $P$. falciparum malaria the sensitivity was $100 \%$ for both tests. The specificity was $95 \%$ for ELISA and $100 \%$ for IFA in non malaria individuals.

The results showed that the ELISA test could be an alternative for IFA for IgG antibodies in the serology of malaria.

\section{AGRADECIMENTOS}

Ao $\mathrm{CNPq}$ - Projeto do Polonoroeste Processo n: $70.0350 / 85$ pelo suporte financeiro.

Ao Laboratório de Malária da SUCEN pelo fornecimento de cultura de P. falciparum no início do trabalho e pelo fornecimento de soros de pacientes com malária.

A Vera de Paula Quartier de Oliveira, Rivaldo de Souza Cardoso e Paulo de Oliveira pela assistência técnica na execução do projeto.

\section{REFERÊNCIAS BIBLIOGRÁFICAS}

1. AMBROISE-THOMAS, P. - Diagnosis and seroepidemiologic studies of malaria by immunofluorescence, and indirect haemagglutination and immunoenzymology. Israel J. med. Sci., 14: 690-691, 1978.

2. AMBROISE-THOMAS, P - L'immunofluorescence dans la serologie du paludisme. WHO/MAL, (953): 16,1981

3. AMBROISE-THOMAS, P.; BILLIAULT, X.; DESGEORGES, P.T. \& BOUTTAZ, M. - Mise en evidence, par une micromethode immuno-enzymologique (ELISA), d'antigènes metaboliques produits "in vitro" par Plasmodium falciparum en culture. WHO/MAL, (930): $1-5,1981$.

4. BEAUDOIN, R.L.; RAMSEY, J.M. \& PACHECO N.D. - Antigens employed in immunodiagnostic tests for the detection of malarial antibodies. WHO/MAL, (952): $1-11,1981$
5. BIDWELL, D.E. \& VOLLER, A. - Malaria diagnosis by enzyme-linked immunosorbent assays. Brit. med. J., 282: 1747-8, 1981.

6. BROWN, G.V.; STACE, J.D. \& ANDERS, R.F. Specificities of antibodies boosted by acute Plasmodium falciparum infection in man. Amer. J. trop. Med. Hyg., 32: 1221-1228, 1983.

7. CLARK, H.F. \& SHEPPARD, C.C. - A dialysis technique for preparing fluorescent antibody. Virology, 20: 642-644, 1963.

8. COLLINS, W.E.; LUNDE, M.N. \& SKINNER, J.C. - Development of antibodies to $\mathbf{P}$. vivax as measured by two different techniques. Amer. J. trop. Med. Hyg., 24: 412-416, 1975

9. COLLINS, W.E. \& SKINNER, J.C. - The indirect fluorescent antibody test for malaria. Amer. J. trop. Med. Hyg., 21: 690-695, 1972.

10. DRUILHE, P. \& MONJOUR, L. - Sérodiagnostic du paludisme par immuno-précipitation. Valeur comparée de différentes techniques d'extraction des antigènes solubles. Sensibilité par rapport à l'immunofluorescence indirecte. C.R. Soc. Biol. (Paris), 169: 1089-1095, 1975.

11. FRANCIS, V.S.; GUPTA, M.M.\& BHAT, P. - Evaluation of a crude soluble antigen from "in vitro" culture of Plasmodium falciparum for ELISA. Tropenmed. Parasit., 33: 240-242, 1982.

12. FRANCO, E.L.F. - Immunoserology of malaria. Apostila. Julho de 1984. 22p.

13. GUPTA, M.M.; SEBASTIAN. M.J.; BHAT, P. \& LOBEL, H.O. - Evaluation of "in vitro" cultured $\mathbf{P}$ falciparum as antigen for malaria serology. J. trop. Med. Hyg., 84: 165-170, 1981.

14. JENSEN, J.B. - Concentration from continuous culture of erythrocytes infected with trophozoites and schizonts of Plasmodium falciparum. Amer. J. trop. Med. Hyg., 27: 1274-1276, 1978.

15. JENSEN, J.B. \& TRAGER, W. - Some recent advances in the cultivation of Plasmodium falciparum. Israel J. med. Sci., 14: 563-570, 1978.

16. KREIER, J.P. - The isolation and fractionation of malaria-infected cells. Bull. Wld. Hlth. Org., 55: 317 $331,1977$.

17. LOBEL, H.O. - Indications for and usefulness of serological techniques in epidemiological investigation and assessment. WHO/MAL, (967): 1-11, 1981.

18. LÓPEZ-ANTUÑANO, F.J. - Falciparum malaria antigen slides for indirect immuno-fluorescence test made from "in vitro" cultures. Trans, roy. Soc. trop. Med. Hyg., 68: 257, 1974.

19. LÓPEZ-ANTUÑANO, F.J. - Estadarización de las pruebas de Inmuno-Fluorescencia Indirecta (IFI) para malaria. PAHO/WHO Interoffice Memorandum, 1984.

20. LUNDE, M.N. \& POWERS, K.G. - The preparation of malaria haemagglutination antigen. Ann. trop. Med. Parasit., 70: 283-291, 1976.

21. MANAWADU, B.R. \& VOLLER, A. - Standardization of the indirect fluorescence antibody test for malaria. Trans. roy. Soc. trop. Med. Hyg., 72: 456-462, 1978.

22. NAKANE, P.K. \& KAWAOI, A. - Peroxidaselabeled antibody a new method of conjugation. J. Histochem. Cytochem., 22: 1084-1091, 1974.

23. PASVOL, G.; WILSON, R.J.M.; SMALLEY, M.E. \& 
FERREIRA, A.W. \& SANCHEZ, M.C.A. - Malária humana: padronização e optimização de testes sorológicos para diagnóstico individual e inquéritos soroepidemiológicos. Rev. Inst. Med. trop. São Paulo, 30(3):137-146, 1988.

BROWN, J. - Separation of viable schizont-infected red cells of Plasmodium falciparum form human blood. Ann. trop. Med. Parasit., 72: 87-88, 1978.

24. QUAKYI, I.A. - The development and validation of an enzyme-linked immunosorbent assay for malaria. Tropenmed. Parasit., 31: 325-333, 1980.

25. QUILICI, M.; DELMONT, J.; RANQUE, J.; ROUGEMONT, A.; MARTARESCHE, B. \& BOISSON, M.E. - Évaluation de l'antigène de Plasmodium falciparum d'origine humaine pour la réaction d'immunofluorescence indirecte dans le paludisme. Bull. Soc. Path. exot., 68: 515-521, 1975.

26. REESE, R.T.; LANGRETH, S.G. \& TRAGER, W. Isolation of stages of the human parasite Plasmodium falciparum from culture and from animal blood. Bull. Wld. Hlth. Org., 57 (suppl. 1): 53-61, 1979.

27. REPORT on the Merieux Foundation/WHO Meeting on Immunological methods in malariology. WHO/MAL, (948): 1-17, 1981.

28. ROFFI, J.; LAFABRIE, B. \& STACH, J.L. - Utilisation d'antigènes purifiès pour le sérodiagnostic et les études épidémiologiques du paludisme humain. Intérêt de la technique ELISA pour la mise en évidence des IgG et des IgM spécifiques. Bull. Soc. Path. exot., 76: 49-68, 1983

29. SAUL, A.; MYLER, P.; ELLIOTT, T.; T. \& KIDSON, C. - Purification of mature schizonts of P. falciparum on colloidal silica gradients. Bull. Wld. HIth. Org., 60: 755-759, 1982.

30. SPENCER, H.C.; COLLINS, W.E.; CHIN, W. \& SKINNER, J.C. - The enzyme-linked immunosorbent assay (ELISA) for malaria. I. The use of in vitrocultured $P$. falciparum as antigen. Amer. J. trop. Med. Hyg., 28: 927-938, 1979.

31. SPENCER, H.C.; COLLINS, W.E. \& SKINNER, J.C. - The enzyme-linked immunosorbent assay (ELlSA) for malaria. Il. Comparison with the malaria indirect fluorescent antibody test (IFA). Amer. J. trop. Med. Hyg., 28: 933-936, 1979.

32. SPENCER, H.C.; COLLINS, W.E.; WARREN, M.; JEFFERY, G.M.; MASON, J.; HUONG, A.Y.; STANFILL, P.S. \& SKINNER, J.C. - The enzymelinked immunosorbent assay (ELISA) for malaria. III. Antibody response in documented $\mathbf{P}$. falciparum infections. Amer. J. trop. Med. Hyg., 30: 747-750, 1981.

33. SULZER, A.J.; WILSON, M. \& HALL, E.C. - Indirect fluorescent antibody tests for parasitic diseases. $V$. An evaluation of a thick-smear antigen in the IFA test for malaria antibodies. Amer. J. trop. Med. Hyg., 18: 199-205, 1969.
34. TANDOM, A.; SAXENA, R.P.; BHATIA, B. \& SAXENA, K.C. - The enzyme-linked immunosorbent assay in the immunodiagnosis of human malaria. Trans. roy. Soc. trop. Med. Hyg., 76: 371-372, 1982.

35. TARGETT, G.A.T. - Antibody response to Plasmodium falciparum malaria: comparison of immunoglobulin concentration antibody titers and antigenicity of different assexual stages of the parasite. Clin. exp. Immunol., 7: 501-517, 1970.

36. TRAGER, W. - Plasmodium falciparum in culture: improved continuous flow method. J. Protozool., 26: 125-129, 1979.

37. TRAGER, W. - Recent developments in enlarging the scale of production of Plasmodium falciparum "in vitro". Bull. Wld. HIth. Org., 57 (suppl. 1): 85-86, 1979.

38. TRAGER, W. \& JENSEN, J.B. - Human malaria parasites in continuous culture. Science, 193: 673-675, 1976.

39. VOLLER, A.; BARTLETT, A. \& BIDWELL, D.E. Enzyme immunoassays for parasitic diseases. Trans. roy. Soc. trop. Med. Hyg., 70: 98-106, 1976.

40. VOLLER, A.; BIDWELL, D.E.; BARTLETT, A. \& EDWARDS, R. - A comparison of isotopic and enzyme immunoassays for tropical parasitic diseases. Trans. roy. Soc. trop. Med. Hyg., 71: 431-437, 1977.

41. VOLLER, A.; BIDWELL, D; HULT, G. \& ENGVALL, E. - A microplate of enzyme-linked immunosorbent assay and its application to malaria. Bull. WId. HIth. Org., 51: 209-211, 1974.

42. VOLLER, A.; CORNILLE-BROGGER, R.; STOREY, J. \& MOLINEAUX, L. - A longitudinal study of P. falciparum malaria in the West African savanna using the ELISA technique. Bull. Wld. Hith. Org., 58: 429-438, 1980.

43. VOLLER, A.; HOLDT, G.; THORS, C. \& ENGVALL, E. - New serological test for malaria antibodies. Brit. med. J., 1: 61, 1975.

44. Willet, G.P. \& CANFIELD, C.J. - Plasmodium falciparum: continuous cultivation of erythrocyte stages in plasma-free culture medium. WHO/MAL, (1002): 1-8, 1983.

45. WILSON, R.J.M. \& LING, I. - Fractionation and characterization of Plasmodium falciparum antigens. Bull. WId. HIth. Org., 57 (suppl. 1): 123-133, 1979.

46. ZUCKERMAN, A. - Current status of the immunology of blood and tissue Protozoa. II. Plasmodium. Exp. Parasit., 42: 374-446, 1977. 